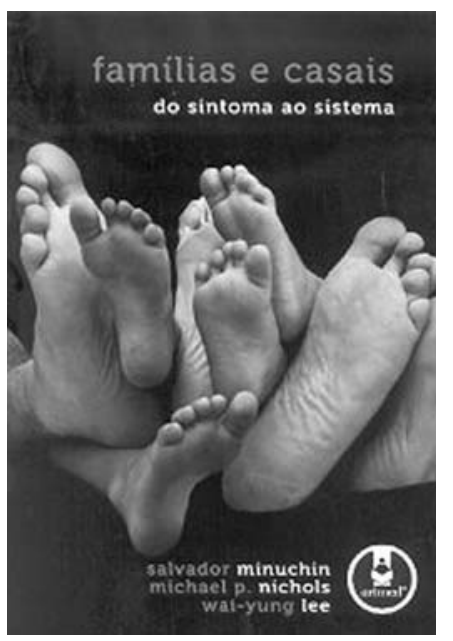

\title{
Famílias e casais: do sintoma ao sistema
}

Salvador Minuchin, Michael P. Nichols e Way-Yung Lee

Porto Alegre, Artmed, 2009, 240 p.

\section{Marcos Hirata Soares*}

* Mestre. Professor, Departamento de Enfermagem, Centro de Ciências da Saúde, Universidade Estadual de Londrina, Londrina, PR.

O livro é baseado na terapia familiar estrutural, um segmento da teoria sistêmica. O modelo estrutural importa os principais conceitos da teoria sistêmica, mas foca na forma como a família delimita as fronteiras entres seus membros (questão dos papéis desempenhados e os limites de cada um). Através de uma explicação de técnicas experimentadas e desenvolvidas pelos autores durante cerca de 5 décadas e de diversos estudos de casos clínicos, o livro se propõe a demonstrar um modelo de quatro etapas para acessar e avaliar a família, direcionando o processo terapêutico com ela.

Embora o sofrimento e os diversos desajustes familiares tenham formas diferentes de entendimento segundo os laços culturais de cada família, os autores sugerem que a explicação mais aceitável para que suas teorias e técnicas sejam validadas transculturalmente é que todas as pessoas estão sujeitas a formas comuns de ver e entender as relações familiares. Assim, os autores, enquanto terapeutas, oferecem às famílias um tipo de estrutura familiar organizadora, capaz de explicar seus dilemas, pois melhora a comunicação e a compreensão mútua em família, fazendo com que elas, ainda, utilizem esse modelo no seu dia a dia, trazendo inovações e ajustando-o às suas maneiras individuais de ser.

Este modelo acima é composto de quatro etapas e tem como meta descobrir o que impede a família de atingir seus objetivos e, então, unir-se a ela para conceber uma visão de como passar da fase atual para onde ela deseja estar. Essa complexa tarefa divide-se em quatro etapas, aqui descritas sucintamente:

1) Descentralizar o problema apresentado e o portador do sintoma. Deve-se fazer com que a família compreenda que o problema apresentado por ela não está relacionado apenas ao mecanismo interno de um de seus membros.

2) Investigar os padrões familiares que mantêm o problema. Explorar o que os membros da família podem estar fazendo para perpetuar o problema, auxiliando os familiares a perceberem como suas ações podem estar mantendo o problema. Essa etapa parte do pressuposto de que os membros da família mudarão seu padrão de relação se conseguirem ver a si mesmos como capazes de ajudar o paciente identificado.

3) Investigar o que os membros da família trazem do passado que ainda influencia o presente. Investigar o passado com foco na estrutura, através de uma exploração breve e focada do passado dos membros adultos da família, com o intuito de auxiliá-los a entender como chegaram à sua visão limitada do presente, de si mesmos e dos outros. Essa etapa é vista como a

Correspondência:

Prof. Marcos Hirata Soares, Departamento de Enfermagem, CCS, Av. Robert Koch, 60, Vila Operária, CEP 860838-350, Londrina, PR. E-mail: mhirata@uel.br Não foram declarados conflitos de interesse associados à publicação desta resenha.

Copyright (C) Revista de Psiquiatria do Rio Grande do Sul - APRS

Recebido em 16/12/2009. Aceito em 21/12/2009. 
continuação das explorações do estilo de relacionamento que o terapeuta e a família desvelaram na etapa anterior.

4) Redefinir o problema e testar opções. Após o desenvolvimento de um quadro inicial dos motivos que mantêm a família bloqueada e de como esse caminho foi tomado, os membros da família e o terapeuta falam sobre quem precisa mudar o quê - e sobre quem tem a disposição de fazê-lo ou não. Essa é uma etapa fundamental para se evitar a resistência às mudanças propostas na terapia.

A partir de 10 exemplos de casos, os autores apresentam a primeira e segunda sessões, assim como a estrutura terapêutica de cada caso (organização familiar, perspectivas individuais, estratégias de intervenção e técnicas usadas). Os casos estão representados pelos seguintes grupos:

1) Crianças problemáticas e seus pais. Nessa parte, chama a atenção o fato de os conflitos entre os pais estarem relacionados às diferentes perspectivas para a maternidade e a paternidade e à existência de excessiva proximidade de um e/ou distanciamento do outro em relação aos filhos.

2) Famílias reconstituídas. Considerando os desafios que essas novas famílias possuem, elas são permeadas por rivalidades complexas, constituindo-se num grande desafio.

3) Casais complementares. A partir dos casos, nota-se o quanto os sintomas das pessoas se associavam à vida complicada de suas famílias e também que os conflitos conjugais eram deslocados para o cuidado com os filhos.

4) Famílias psicossomáticas. Há uma relação entre os processos emocionais e fisiológicos, mediada pelos padrões estruturais familiares e pela hierarquia geracional, ou seja, famílias com demasiado envolvimento emocional e críticas constantes produzem estimulação fisiológica que influencia o curso de doenças físicas e/ou transtornos mentais. Há também uma crítica ao termo psicossomático usado no Diagnostic and Statistical Manual of Mental Disorders - 4th edition (DSM-IV), pois sugere uma dicotomia entre doenças orgânicas e mentais, contrária à relação de circularidade, defendida pela abordagem sistêmica. A chave para trabalhar com famílias psicossomáticas é focar a transformação de um sintoma psicossomático em um conflito interpessoal manifesto.

5) A família e os serviços sociais. A terapia familiar opera no pressuposto de que os adolescentes dependentes químicos são parte de um contexto familiar e que mudanças no indivíduo requerem uma mudança na relação entre o adolescente e sua família. Há uma ressalva de que a abordagem sistêmica não é superior às outras, mas possui uma profundidade e utilidade para superar o desenvolvimento da dependência.

O livro, resultado de cerca de 5 décadas de pesquisa e trabalho, não apresenta um resgate teórico sobre a teoria sistêmica nem sobre o modelo estrutural, que é derivado dela, mas apresenta de forma bem sintetizada, clara e objetiva o conteúdo necessariamente intrínseco à prática da terapia familiar. Trata-se, portanto, não de uma leitura básica, mas sim de um livro para aqueles que possuem formação em terapia familiar.

Através dos exemplos de casos, o livro expõe de forma bem prática a experiência dos autores e criadores de um método próprio para a realização da terapia familiar, muito bem embasado e apoiado em outras diversas estratégias de trabalho com famílias. Uma característica que chama a atenção é a exposição de diversas estratégias não adequadas que foram usadas pelos autores, demonstrando humildade e um posicionamento do terapeuta enquanto ser humano, passível de erros, mas também de grande aprendizado e evolução.

Esse enfoque humanístico em psicoterapia vem sendo uma característica constante nas atuais correntes psicoterápicas em saúde mental, reforçando as ideias iniciais de Carl Rogers, por exemplo, acerca do aspecto interpessoal em psicoterapia. 